\title{
Gastrostomy tube placement by radiological versus endoscopic methods in an acute care setting: A retrospective review of frequency, indications, complications and outcomes
}

\author{
Amy Galaski BASc RD ${ }^{1 *}$, Wei Wei Peng BASc BA RD ${ }^{1 *}$, Michelle Ellis MEd CDE RD ${ }^{1}$, \\ Pauline Darling PhD RD ${ }^{1,2,3}$, Andrew Common $\mathrm{MD}^{4,5}$, Emma Tucker MSc RD ${ }^{1}$
}

\begin{abstract}
A Galaski, WW Peng, M Ellis, P Darling, A Common, E Tucker. Gastrostomy tube placement by radiological versus endoscopic methods in an acute care setting: A retrospective review of frequency, indications, complications and outcomes. Can J Gastroenterol 2009;23(2):109-114.
\end{abstract}

OBJECTIVES: To describe the current practice of placing gastrostomy tubes (endoscopic and radiological), patient characteristics, indications for enteral support, complications and outcomes over a 13-month period, and explore factors that influenced complications and outcomes. Second, to provide Canadian data regarding feeding tube placement because no current literature reflecting these practices for Canadian hospitals is available.

METHODS: Retrospective chart reviews were conducted. Patients who had initial percutaneous endoscopic gastrostomy (PEG) or percutaneous radiological gastrostomy (PRG) tubes inserted for nutritional purposes were included in the study.

RESULTS: A total of 136 charts which included 30 PEG and 44 PRG procedures were reviewed. The PRG group was older than the PEG group (mean $[ \pm \mathrm{SD}]$ age $68 \pm 19$ years versus $55 \pm 21$ years, respectively; $\mathrm{P}=0.008)$. Patients in PEG group had longer lengths of hospital stay and more intensive care unit admissions than the PRG group $(\mathrm{P}=0.029)$. The main reason for tube insertion was dysphagia/aspiration (PEG [60\%] and PRG [77\%]). Minor complications were comparable between the two groups $(\mathrm{P}=0.678)$. There were three cases of major complications overall. More subjects in the PRG group died $(18 \%)$ while in hospital than in the PEG group (3\%) $(\mathrm{P}=0.055)$. No procedure-related deaths occured in either group.

CONCLUSIONS: Both methods of tube insertion provided a safe route for nutrition delivery despite a significant cost differential with PEGs costing 44\% more than PRGs. Characteristics such as age, presence of ascites and severity of disease influenced the method of insertion despite the lack of current guidelines. Overall, the present study provides new descriptive data in a Canadian context.
L'installation d'une sonde de gastrostomie par radiologie plutôt que par endoscopie en soins actifs : Une analyse rétrospective de la fréquence, des indications, des complications et des issues

OBJECTIFS : Décrire la pratique actuelle d'installation d'une sonde de gastrostomie (par voie endoscopique ou radiologique), les caractéristiques des patients, les indications de soutien entérique, les complications et les issues sur une période de 13 mois et explorer les facteurs qui influent sur les complications et les issues. Ensuite, fournir des données canadiennes au sujet de l'installation des sondes d'alimentation parce qu'il n'existe pas de publications à jour sur ces pratiques dans les hôpitaux canadiens.

MÉTHODOLOGIE : Les chercheurs ont effectué une analyse rétrospective des dossiers. Ils ont inclus dans l'étude les patients qui avaient subi une gastrostomie endoscopique percutanée (GEP) ou une gastrostomie radiologique percutanée (GRP) pour des besoins d'alimentation.

RÉSULTATS : Au total, les chercheurs ont analysé 136 dossiers, y compris 30 GEP et 44 GRP. Le groupe GRP était plus âgé que le groupe GEP (âge moyen [ $[E$ ÉT] de $68 \pm 19$ ans par rapport à $55 \pm 21$ ans, respectivement; $\mathrm{P}=0,008)$. Les patients du groupe GEP étaient hospitalisés plus longtemps et allaient davantage en soins intensifs que le groupe GRP $(P=0,029)$. La principale raison pour installer la sonde était la dysphagie ou l'aspiration (GEP [60\%] et GRP [77 \%]). Les complications mineures étaient comparables entre les deux groupes $(\mathrm{P}=0,678)$. Dans l'ensemble, il y a eu trois cas de graves complications. Plus de sujets du groupe GRP sont décédés (18\%) pendant l'hospitalisation que dans le groupe GEP $(3 \%)(\mathrm{P}=0,055)$. Aucun décès relié à l'intervention ne s'est produit dans l'un ou l'autre groupe. CONCLUSIONS : Les deux méthodes d'installation des sondes étaient sécuritaires pour l'alimentation malgré une marge importante entre les coûts, la GEP étant 44 \% plus coûteuse que la GRP. Des caractéristiques comme l'âge, la présence d'ascites et la gravité de la maladie influaient sur le mode d'installation malgré l'absence de lignes directrices à jour. Dans l'ensemble, la présente étude fournit de nouvelles données descriptives dans un contexte canadien.

Key Words: Feeding tubes; Gastrostomy; Percutaneous endoscopic gastrostomy; Percutaneous radiological gastrostomy

E nteral feeding is a method by which nutrients are provided to the gastrointestinal (GI) tract via a tube. This form of feeding is indicated for those who are unable to ingest adequate amounts of food to meet their nutritional requirements and who have functional GI tracts. Gastrostomies or jejunostomies are used in people who are expected to require long-term nutritional support (generally longer than two weeks), or have impairments of the upper regions of the GI tract. The benefits of enteral nutrition support demonstrated by both human and

animal studies include improved nutritional outcome, preservation of gut integrity and function, and a reduction in associated morbidity (1). Although each method is indicated for slightly different reasons, the procedure of insertion is similar for both methods. In the present study, an intraprocedural description and comparison of gastrostomy methods of insertion is presented.

Two methods of insertion are used for gastrostomies: endoscopic and fluoroscopic. The percutaneous endoscopic

\footnotetext{
*Co-first authors; ${ }^{2}$ Department of Nutrition; ${ }^{2}$ Keenan Research Centre; Li Ka Shing Knowledge Institute; ${ }^{3}$ Department of Medical Imaging,

St Michael's Hospital; ${ }^{4}$ Departments of Nutritional Sciences and ${ }^{5}$ Medicine, University of Toronto, Toronto, Ontario

Correspondence: Michelle Ellis, Department of General Medicine, St Michael's Hospital, 30 Bond Street, Toronto, Ontario

M5B 1W8. Telephone 416-360-4000 ext 6467, fax 416-864-5149, e-mail ellism@smh.toronto.on.ca

Received for publication September 5, 2008. Accepted November 3, 2008
} 
TABLE 1

Patient characteristics

\begin{tabular}{|c|c|c|c|}
\hline Characteristic & $\begin{array}{l}\text { Percutaneous endoscopic } \\
\text { gastrostomy }(n=30)\end{array}$ & $\begin{array}{l}\text { Percutaneous radiological } \\
\text { gastrostomy }(n=44)\end{array}$ & $\mathbf{P}$ \\
\hline Age, years (mean $\pm \mathrm{SD}$ ) & $55 \pm 21$ & $65 \pm 19$ & $0.008^{*}$ \\
\hline Men, n (\%) & $19(63.3)$ & $31(70.5)$ & $0.521^{\dagger}$ \\
\hline Weight, $\mathrm{kg}($ mean $\pm \mathrm{SD}) \S$ & $71.1 \pm 17.3$ & $65.2 \pm 18.7$ & $0.175^{*}$ \\
\hline Body mass index, $\mathrm{kg} / \mathrm{m}^{2 \ddagger}$ & $26.1 \pm 4.2$ & $24 \pm 6.1$ & $0.139^{*}$ \\
\hline Intensive care unit admission & $25(83.3)$ & $18(40.9)$ & $<0.001^{*}$ \\
\hline Ascites & $0(0)$ & $4(9.1)$ & $0.090^{\dagger}$ \\
\hline Diagnosis, n (\%) & & & $0.019^{\dagger}$ \\
\hline Trauma & $11(36.7)$ & $2(4.5)$ & \\
\hline Aspiration pneumonia & $2(6.7)$ & $3(6.8)$ & \\
\hline HIV & $0(0)$ & $3(6.8)$ & \\
\hline Failure to thrive & $1(3.3)$ & $1(2.3)$ & \\
\hline Coronary artery disease & $0(0)$ & $8(18.2)$ & \\
\hline Sepsis & $0(0)$ & $1(2.3)$ & \\
\hline Neurological disorder & $8(26.7)$ & $15(34.1)$ & \\
\hline Head/neck cancer & $5(16.7)$ & $3(6.8)$ & \\
\hline Lung cancer & $0(0)$ & $2(4.5)$ & \\
\hline Prostate cancer & $1(3.3)$ & $0(0)$ & \\
\hline Chronic obstructive pulmonary disease & $0(0)$ & $1(2.3)$ & \\
\hline
\end{tabular}

*P value based on $\mathrm{t}$ test; ${ }^{\dagger} P$ value based on $\chi^{2}$ test; ${ }^{\ddagger} n=27$ for percutaneous endoscopic gastrostomy ( 3 cases missing), $n=32$ for percutaneous radiological gastrostomy (12 cases missing); $\S_{n=42}$ for percutaneous radiological gastrostomy ( 2 cases missing)

gastrostomy (PEG) method was introduced in 1980 (2). The percutaneous radiological gastrostomy (PRG), which uses fluoroscopic guidance, was first performed in 1981 (3), and was devised as an alternative to PEG in cases in which passing an endoscope is difficult or risky (2-4). The literature supports PEG and PRG as safe and effective procedures with most complications being minor and easily treatable. Studies related to PEGs and PRGs divide complications into minor and major categories (3,5-12). Minor complications, referred to as local and non-life-threatening, are comprised of such categories as stoma leakage, wound infection, bleeding, tube dislodgement, pain, gastroesophageal reflux and tube blockage (3,5-12). Major complications are those that are systemic and lifethreatening, and include gastrocolic-cutaneous fistula, necrotizing fasciitis, tumour implantation in the stoma site, cardiac failure with hypoxia (resuscitated), gastric hemorrhage, peritonitis, cellulitis, hematoma, internal bleeding, catheter dislodgement into the peritoneal cavity and aspiration pneumonia $(3,5-12)$.

Previous studies that have reported complication frequencies lack a Canadian perspective, and have been limited to individual patient populations. In addition, they have conflicting findings regarding the use of antibiotic prophylaxis (13-16) and have included limited outcomes $(3,7,8,10-12)$. Therefore, the purpose of the present study was to describe the indications for both PEG and PRG, and their complications and outcomes in a diverse patient population at an inner-city hospital with a designated trauma centre in Toronto, Ontario.

\section{METHODS}

Study design

The present study was a retrospective chart review and approved by the Research Ethics Board of St Michael's Hospital (SMH), Toronto, Ontario, in December 2005.

A subject list was generated from the Decision Support Services Database (DSSD) based on the code for abdominal device insertion. The DSSD is a database at SMH that contains the records of patient visits and procedures. To ensure informational accuracy, the Decision Support Services group audits data monthly and quarterly. In total, the subject list for the present study contained 137 patients who underwent any abdominal device insertion at SMH between December 1, 2004, and December 31, 2005.

Eligibility criteria included all patients who underwent initial gastrostomy tube insertion for nutritional purposes (either sole or supplemental) during a 13-month period between December 1, 2004, and December 31, 2005. To eliminate subjects who underwent non-gastrostomy-related internal device insertions, the subject list was screened using the Clinical Database (a separate hospital database from the DSSD).

Information related to patient demographics and clinical characteristics, the tube insertion procedure practices, minor complications (defined as non-life-threatening within the first 30 days of gastrostomy tube insertion and before hospital discharge), major complications (defined as life-threatening within the first 30 days of gastrostomy insertion and before hospital discharge), as well as patient outcomes, were collected $(3,5-12,17,18)$. 
TABLE 2

\begin{tabular}{|c|c|c|c|}
\hline & PEG $(n=30)$ & PRG $(n=44)$ & $\mathbf{P}^{*}$ \\
\hline Antibiotic prophylaxis & $15(50.0)$ & $3(6.8)$ & $<0.001$ \\
\hline Other antibiotic & $7(23.3)$ & $19(43.2)$ & 0.079 \\
\hline Reason for insertion & & & 0.022 \\
\hline Dysphagia/aspiration & $18(60)$ & $34(77.3)$ & \\
\hline Loss of consciousness & $7(23.3)$ & $3(6.8)$ & \\
\hline Cognition & $3(10.0)$ & $0(0)$ & \\
\hline Suboptimal oral intake & $0(0)$ & $4(9.1)$ & \\
\hline Intubation & $2(6.7)$ & $3(6.8)$ & \\
\hline $\begin{array}{l}\text { Insertion during intensive } \\
\text { care unit stay }\end{array}$ & $9(30.0)$ & $5(11.4)$ & 0.002 \\
\hline
\end{tabular}

Data presented as $n(\%) ;{ }^{*} P$ values based on $\chi^{2}$ tests

TABLE 3

Frequency of cause of death

\begin{tabular}{ll}
\hline Cause of death & $\mathbf{n}(\%)$ \\
\hline Respiratory failure & $2(2.7)$ \\
Aspiration & $1(1.4)$ \\
Sepsis & $1(1.4)$ \\
Sepsis secondary to aspiration & $1(1.4)$ \\
Bacteremia & $1(1.4)$ \\
HIVIAIDS & $1(1.4)$ \\
Metastatic lung cancer & $1(1.4)$ \\
Coronary artery disease & $1(1.4)$ \\
Total deaths & $9(12.2)$ \\
\hline
\end{tabular}

Statistical analysis

$\chi^{2}$ tests and $t$ tests were conducted to compare patient characteristics, tube insertion procedure, complications and outcomes between the PEG and PRG groups. The $\chi^{2}$ test was applied to relationships between tube insertion procedure variables and complications. Statistical significance was set at $\alpha=0.10$, given the small sample size of 74 subjects. All statistical analyses were performed using SPSS for Windows version 14.0 (SPSS Inc, USA).

\section{Patient population}

\section{RESULTS}

One hundred thirty-seven subjects were identified as eligible by the Decision Support Services group. One hundred thirtysix subject charts were reviewed; one chart was not available. Sixty-two initial subjects were excluded because they did not meet the inclusion criteria of having new gastrostomy tubes inserted for the delivery of nutrition. Seventy-four subjects were included in the study, of whom 30 underwent PEG and 44 underwent PRGs.

As indicated in Table 1, subjects in the PRG group were significantly older than the subjects in the PEG group ( $\mathrm{P}=0.008)$. Subjects who received PEGs had significantly longer lengths of hospital stay $(\mathrm{P}=0.029)$ and more admissions to the intensive care unit $(\mathrm{ICU})(\mathrm{P}<0.001)$ than those who received PRGs. Table 1 also shows the variety of diagnoses associated with each insertion method.

Tube insertion procedure

Antibiotics were not prescribed consistently as prophylaxis for infection in either the PRG or PEG groups. Subjects in the

\section{TABLE 4}

\begin{tabular}{|c|c|c|c|}
\hline Minor complication & PEG $(n=30)$ & PRG $(n=44)$ & $\mathbf{P}^{*}$ \\
\hline Stoma leakage & $5(16.7)$ & $5(11.4)$ & 0.512 \\
\hline Wound infection & $2(6.7)$ & $2(4.5)$ & 0.692 \\
\hline Bleeding stoma site & $4(13.3)$ & $3(6.8)$ & 0.347 \\
\hline Tube dislodgement & $2(6.7)$ & $2(4.5)$ & 0.692 \\
\hline Reflux & $1(3.3)$ & $1(2.3)$ & 0.782 \\
\hline Tube blockage & $0(0)$ & $2(4.5)$ & 0.236 \\
\hline Hemoptysis & $1(3.3)$ & $0(0)$ & 0.341 \\
\hline Erythemic hard site & $0(0)$ & $1(2.3)$ & 0.341 \\
\hline Overall episodes & $15(50.0)$ & $16(36.3)$ & 0.481 \\
\hline Overall patients & $8(26.7)$ & $11(25.0)$ & 0.678 \\
\hline
\end{tabular}

Data presented as $n$ (\%); * $P$ value based on $\chi^{2}$ test

PEG group were more likely to receive prophylactic antibiotic therapy; however, 19 of the 44 (43\%) patients who received a PRG were already on antibiotics before the procedure compared with only seven of the 30 (23\%) patients in the PEG group (Table 2). Rates of infection were not significantly different between the two groups $(\mathrm{P}=0.692)$.

The main indication for tube insertion in both groups was dysphagia/aspiration. More subjects in the PEG group (30\%) had gastrostomy tubes inserted in the ICU than those in the PRG group (11.4\%; $\mathrm{P}=0.002$ ).

\section{Outcomes}

Statistically significantly more subjects in the PRG group $(n=8$ [18.1\%]) died during their hospital stay than in the PEG group $(\mathrm{n}=1[3.3 \%])(\mathrm{P}=0.055)$. Table 3 details the causes of death.

The overall frequency of minor complication episodes and the total number of patients with minor complications were not statistically significantly different between the PEG and PRG groups ( $\mathrm{P}=0.481 ; \mathrm{P}=0.678$, respectively) (Table 4).

Overall, there were three cases of major complications. One subject in the PEG group developed cellulitis. In the PRG group, one subject developed peritonitis and one subject developed aspiration pneumonia.

\section{Factors associated with complications}

Factors that may influence complications include age, ICU stay, tube insertion during ICU stay and body mass index. The relationships between these factors and the complications were analyzed. As indicated in Table 5, there were no statistically significant relationships found among complications and age, ICU stay, insertion during ICU stay or body mass index.

\section{Procedure costs}

A cost breakdown of PEG and PRG procedures based on materials, personnel wages and tube costs is shown in Table 6 . There was a $\$ 184.46$ cost difference between the two procedures, with PEG being more costly.

\section{DISCUSSION}

There are obvious benefits to each method of gastrostomy insertion. Endoscopic tube insertions have diagnostic capabilities that enable physicians to visualize the anatomy of the stomach and identify abnormalities. The radiological procedure has very few contraindications and therefore can be used in a larger 
TABLE 5

Relationships between age, intensive care unit (ICU) stay, ICU versus non-ICU tube insertion, body mass index (BMI) and complications

\begin{tabular}{|c|c|c|c|c|c|c|}
\hline & \multicolumn{3}{|c|}{ Minor complications, $\mathrm{n}(\%)$} & \multicolumn{3}{|c|}{ Major complications, $\mathrm{n}(\%)$} \\
\hline & Yes & No & $\mathbf{P}$ & Yes & No & $\mathbf{P}$ \\
\hline Age $^{*}$, years (mean $\left.\pm S D\right)$ & $62 \pm 21$ & $63 \pm 20$ & 0.926 & & & \\
\hline ICU stay ${ }^{\dagger}$ & & & 0.661 & & & 0.759 \\
\hline Yes & $12(16.4)$ & $31(42.5)$ & & $2(2.7)$ & $41(35.4)$ & \\
\hline No & $7(9.6)$ & $23(31.5)$ & & $1(1.4)$ & $30(40.4)$ & \\
\hline $\mathrm{ICU}_{\text {versus non-ICU tube insertion }}^{\dagger}$ & & & 0.693 & & & 0.883 \\
\hline No ICU stay & $7(9.6)$ & $23(31.5)$ & & $1(1.4)$ & $30(40.5)$ & \\
\hline Unknown & $1(1.4)$ & $5(6.8)$ & & $0(0)$ & $6(8.1)$ & \\
\hline $\mathrm{BMI}^{\dagger}$ & & & 0.343 & & & 0.323 \\
\hline Underweight (BMI $<18.5 \mathrm{~kg} / \mathrm{m}^{2}$ ) & $0(0)$ & $6(10.2)$ & & $0(0)$ & $6(10.2)$ & \\
\hline Normal (BMI $18.5 \mathrm{~kg} / \mathrm{m}^{2}-24.9 \mathrm{~kg} / \mathrm{m}^{2}$ ) & $6(10.2)$ & $16(27.1)$ & & $2(3.4)$ & $20(33.9)$ & \\
\hline
\end{tabular}

${ }^{*} P$ value based on $\mathrm{t}$ test; ${ }^{\dagger} P$ value based on $\chi^{2}$ test

TABLE 6

Procedure costs of percutaneous endoscopic gastrostomy (PEG) versus percutaneous radiological gastrostomy (PRG)

\begin{tabular}{lrr}
\hline & PEG & PRG \\
\hline Procedure & 271.34 & 157.54 \\
Materials & 59.00 & 59.00 \\
Wages & 78.55 & 78.60 \\
Tube cost & 172.52 & 100.75 \\
Total & 591.41 & 406.95 \\
\hline
\end{tabular}

Costs presented in Canadian dollars for procedures at the St Michael's Hospital, Toronto, Ontario

patient population (19). At SMH, the costs of the procedures are also different, with PEGs being $43 \%$ more expensive than PRGs.

While the patients who underwent PRGs were older and had a greater incidence of ascites, those who received a PEG had more severe conditions such as head and neck cancer, trauma, as well as wasting in HIV/AIDS, and were more likely to be admitted to the ICU. The occurrence of minor complications was comparable between the two groups. There were a few major complications associated with both insertion methods. Mortality was greater within the PRG group; however, as previously indicated, this method of insertion has very few contraindications and thus can be performed on subjects with a wide variety of diagnoses and at varying stages of disease (19). Also, the mean age of the PRG group was greater ( $68 \pm 19$ years) than the mean age of the PEG group ( $55 \pm 21$ years), which may have contributed to increased mortality.

The sample size of the present study is comparable with the sample sizes of similar reports in the literature reviewed, given the relatively short study period. Documented diagnoses related to PEG tube insertions are vast and include dementia, stroke, dysphagia, oral and head/neck tumours, trauma and wasting in HIV/AIDS $(2,5-9,20,21)$. The most common diagnosis associated with the PRG method is reported to be malignancy in the head and neck region, a condition that prevents the passage of an endoscope $(3,7,10-12)$. The categories of primary diagnoses related to gastrostomy insertions observed in the present study are consistent with those documented in the literature $(2,3,5-12,20,21)$. However, three points of difference occurred. First, because there are no set guidelines related to gastrostomy tube insertion at the $\mathrm{SMH}$, procedure type is based on availability or physician preference of the service (ie, endoscopy versus radiology); the PRG method was not reserved for patients with head and neck malignancies. In fact, more subjects in the PEG group ( $\mathrm{n}=5$ [16.7\%]) had head and neck cancer than those in the PRG group $(n=3[6.8 \%])$. Second, with the exception of a few studies $(10,17,18)$, most of the studies in the literature examined gastrostomy placement only within a single patient population or diagnosis. However, because the present study was conducted at a large inner-city hospital with a designated trauma centre, gastrostomy tube insertion was described in a large cross-section of diagnosis categories. Finally, while the literature describes the diagnoses present in sample populations, there is limited description beyond this that would indicate the severity of the illness or condition. In addition to documenting diagnoses, the present study also described factors such as length of hospital stay, admission to the ICU and presence of ascites at the time of tube insertion. The PEG group contained more people with trauma and head and neck cancer diagnoses, longer length of hospital stays and more ICU admissions than the subjects in the PRG group, which may indicate that the PEG group contained subjects with more severe medical conditions than the PRG group. Because PEG tubes can be inserted at the bedside, at the time of the present study, all gastrostomy tube insertions in the ICU were completed via the endoscopic method.

The older mean age of the PRG group may be related to the increased difficulty of passing an endoscope in the elderly population. Because the passing of an endoscope during a PEG procedure may disrupt esophageal varices common in patients with hepatic hypertension-related ascites, PRGs were more commonly used in these patients. When none of the above mentioned factors existed, gastrostomy tube placement was completed by the most readily available service. 
Because peristomal wound infection is a complication that can occur after gastrostomy tube insertion, it is believed by some that providing a dose of antibiotic prophylaxis before the procedure may reduce subsequent infection (13). However, use of antibiotic prophylaxis in the PRG population was studied very little before the present study period (2005-2006). While $50 \%$ of the PEG subjects in the present study received antibiotic prophylaxis, only 7\% of subjects in the PRG group received antibiotics, most likely due to antibiotic prophylaxis not being routinely used with the PRG procedure in our hospital, and the fact that $43 \%$ of the PRG group versus $23 \%$ of the PEG group were already on antibiotics for other medical reasons before tube insertion. Despite the findings in the literature, no significant relationship was found between prophylactic antibiotic use and wound infection in the present study. Again, this finding may be confounded by the high number of patients already on antibiotics or due to the small number of subjects $(n=4$ [5\%]) who developed infections. If fewer patients had been on antibiotics before tube insertion, it would be interesting to determine if a higher rate of prophylactic antibiotic use would have been found given the good evidence of its benefit in the literature (21). Although a recent increase in the incidence of methicillin-resistant Staphylococcus aureus infections has raised controversy with regard to antibiotic prophylaxis, the meta-analysis by Lipp and Lusardi (22) concluded that prophylactic antibiotics significantly reduced the incidence of peristomal infection in 10 randomized clinical trials.

While the literature reports minor complications for PEGs range from $0 \%$ to $27.1 \%(5-8,12,17,18)$ and ranging from $23 \%$ to $46 \%$ for PRGs $(2,6,10)$, the methods of reporting complication rates were inconsistent. Complication rates have been reported as both total episodes of complications and the total number of patients who had complications (8), only the total number of patients who had complications (12) or were unclear whether the reported complication rates were based on total episodes or total number of patients $(5-7,10,11,17,20)$.

When comparing the overall number of episodes of minor complications in the PEG group ( $\mathrm{n}=15$ [50\%]) with the results documented in the literature, the rate seems quite high. However, the number of people who had minor complications $(\mathrm{n}=8[26.7 \%])$ is comparable. In the PRG group, both the total number of episodes $(n=16[36.3 \%])$ and the total number of people $(\mathrm{n}=11[25.0 \%])$ with complications are comparable with the rates documented in the literature. In contrast to the literature, the rates of minor complications within the present study were not found to be significantly different between the PRG and PEG groups.

In the literature, patients with more severe diseases (ie, head and neck cancer) received PRGs. Furthermore, the PRG groups had higher complication rates than the PEG groups. In our study, however, patients with more severe conditions were placed in the PEG group, which had a minor complication rate comparable with that of the PRG group.

The major complication rates of both the PEG $(n=1[3.3 \%])$ and PRG $(n=2[4.5 \%])$ groups fell within the ranges documented in the literature $(0 \%$ to $8 \% ; 1.4 \%$ to $5.6 \%$, respectively) $(5-8,12,17,18)$. In total, there were only three cases of major complications, and none of these subjects had more than one major complication. The PRG patient who had aspiration pneumonia passed away in the hospital and it cannot be ruled out that the aspiration event was independent of tube feeding (ie, the patient aspirated his/her own secretions). The other two patients, one in the PEG group with cellulitis and the other in the PRG group with peritonitis, both survived the hospital admission.

The literature reports both disease-related mortality $(7,10,11)$, and to a lesser extent, procedure-related mortality $(3,12)$. In the present study, the mortality rates before hospital discharge were $3.3 \%$ in the PEG group and $18.2 \%$ in the PRG group $(\mathrm{P}=0.055)$ over the 30 -day follow-up period. These rates are similar to those reported in the literature within the same time frame $(7,10-12)$. Due to the retrospective nature of the present study, it was difficult to distinguish disease-related mortality from procedure-related mortality. However, by examining the causes of death in the present study, it can be speculated that most are disease-related, which concurs with the literature (17). Also, because age is the primary predictor of mortality, it is possible that more patient deaths occurred in the PRG group secondary to the significantly older age of this group. Future research may want to focus on identifying patients who will benefit most from PRGs, thereby avoiding unnecessary procedures in patients with a short life expectancy.

Because there were few relationships between variables statistically analyzed in the literature (10), it is difficult to make any comparisons regarding the relationships tested in the present study. Although the relationships examined in the present study were not statistically significant, it is most likely secondary to the limited sample sizes of the variables analyzed. Therefore, these relationships could be re-examined within the context of a larger sample size.

The present Canadian study was the first to describe the indications for both methods of gastrostomy insertion and their complications and outcomes in a diverse patient population at an inner-city hospital within a designated trauma centre. The limitations of the present study are primarily a result of the retrospective study design. The control of information availability was limited and, thus, missing data and further explanations of data were not obtained. In addition, only the complications and outcomes that occurred during the subjects' hospital stay, not postdischarge, were obtained. Also, the sample size was inadequate to analyze the risk factors influencing outcomes. Thus, to gain more detailed information that would contribute to a more complete comparison and analysis of both methods of gastrostomy insertion, the current study time frame could be expanded. In addition, an examination of relationships such as the use of antibiotics and rate of infections in the two groups, feeding initiation times and complications, postdischarge complications and mortality, postdischarge nutritional follow-up and readmission rates should be included.

\section{CONCLUSION}

In the present study, there were few major complications associated with both endoscopically and fluoroscopically placed gastrostomies. Minor complications were comparable between the two groups. Mortality was greater within the PRG group; however, the deaths cannot be directly linked to the procedure itself. The age of the patients in the PRG group was also significantly greater than in the PEG group. The results of the study show that, despite the difference in cost between the two methods of insertion, there was no difference in complication rates between the PEG and PRG groups and that both insertion methods are a safe route for nutritional delivery.

While the subjects in the PRG group were older and had a greater incidence of ascites, those in the PEG group had more severe conditions and more admissions to the ICU. Antibiotic 
prophylaxes were more likely to be used in the PEG group; however, there were more subjects in the PRG group who received antibiotics for other reasons at time of insertion.

The present study provides new descriptive data in a Canadian context. While there are no current guidelines related to gastrostomy use, factors such as age, presence of ascites and severity of condition seemed to influence the type of gastrostomy placed. Therefore, this information may be useful for health care providers when creating gastrostomy practice guidelines to standardize practice, potentially to reduce complications and improve overall patient outcomes.

\section{REFERENCES}

1. DiSario JA. Endoscopic approaches to enteral nutritional support. Best Pract Res Clin Gastroenterol 2006;20:605-30.

2. Löser C, Aschlb G, Hebuternec X, et al. ESPEN guidelines on artificial enteral nutrition - Percutaneous endoscopic gastrostomy (PEG). Clin Nutr 2005;24:848-61.

3. De Baere T, Chapot R, Kuoch V, et al. Percutaneous gastrostomy with fluoroscopic guidance: Single-centre experience in 500 consecutive cancer patients. Radiology 1999;210:651-4.

4. Ozmen MN, Akhan O. Percutaneous radiologic gastrostomy. Eur J Radiol 2002;43:186-95.

5. Hujala K, Sipila J, Pulkkinen J, Grenman R. Early percutaneous endoscopic gastrostomy nutrition in head and neck cancer patients. Acta Otolaryngol 2004;124:847-50.

6. Chandu A, Smith ACH, Douglas M. Percutaneous endoscopic gastrostomy in patients undergoing resection for oral tumors: A retrospective review of complications and outcomes. J Oral Maxillofac Surg 2003;61:1279-84.

7. Neeff M, Crowder VL, McIvor NP, Chaplin JM, Morton RP. Comparison of the use of endoscopic and radiologic gastrostomy in a single head and neck cancer unit. ANZ J Surg 2003;73:590-3.

8. Dwyer KM, Watts DD, Thurber JS, Benoit RS, Fakhry SM. Percutaneous endoscopic gastrostomy: The preferred method of elective feeding tube placement in trauma patients. J Trauma 2002;52:26-32.

9. Stockeld D, Fagerberg J, Granström L, Backman L. Percutaneous endoscopic gastrostomy for nutrition in patients with oesophageal cancer. Eur J Surg 2001;167:839-44.
10. Silas AM, Pearce LF, Lestina LS, et al. Percutaneous radiologic gastrostomy versus percutaneous endoscopic gastrostomy: A comparison of indications, complications and outcomes in 370 patients. Eur J Radiol 2005;56:84-90.

11. Magné N, Marcy PY, Foa C, et al. Comparison between nasogastric tube feeding and percutaneous fluoroscopic gastrostomy in advanced head and neck cancer patients. Eur Arch Otorhinolaryngol 2001;258:89-92.

12. Möller P, Lindberg C-G, Zilling T. Gastrostomy by various techniques: Evaluation of indications, outcome, and complications. Scand J Gastroenterol 1999;10:1050-4.

13. Sharma VK, Howden CW. Meta-analysis of randomized, controlled trials of antibiotic prophylaxis before percutaneous endoscopic gastrostomy. Am J Gastroenterol 2000;95:3133-6.

14. Stein J, Schulte-Bockholt A, Sabin M, Keymyling M. A randomized prospective trial of immediate vs. next-day feeding after percutaneous endoscopic gastrostomy in intensive care patients. Intensive Care Med 2002;28:1656-60.

15. McCarter TL, Condon SC, Aguilar RC, Gibson DJ, Yang KC. Randomized prospective trial of early versus delayed feeding after percutaneous endoscopic gastrostomy placement. Am J Gastroenterol 1998;93:419-21.

16. Chowdhry U, Barde CJ, Markert R, Gopalswamy N. Percutaneous endoscopic gastrostomy: A randomized prospective comparison of early and delayed feeding. Gastrointest Endosc 1996;44:164-7.

17. Löser C, Wolters S, Fölsch UR. Enteral long-term nutrition via percutaneous endoscopic gastrostomy (PEG) in 210 patients A four-year prospective study. Dig Dis Sci 1998;43:2549-57.

18. Rimon E, Kagansky N, Levy S. Percutaneous endoscopic gastrostomy evidence of different prognosis in various patient subgroups. Age Ageing 2005;34:353-7.

19. Wollman B, D'Agostino H, et al. Radiologic, endoscopic and surgical gastrostomy: An institutional evaluation and meta-analysis of the literature. Radiology 1995:197:699-704.

20. Ha I, Hauge T. Percutaneous endoscopic gastrostomy (PEG) for enteral nutrition in patients with stroke. Scand J Gastroenterol 2003;9:962-966.

21. Dharmarajan TS, Unnikrishnan D, Pitchnmoni CS. Percutaneous endoscopic gastrostomy and outcome in dementia. Am J Gastroenterol 2001;96:2556-63.

22. Lipp A, Lusardi G. Systemic antimicrobial prophylaxis for percutaneous endoscopic gastrostomy. Cochrane Database Syst Rev 2006;18:CD005571. 


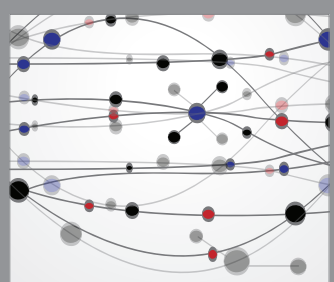

The Scientific World Journal
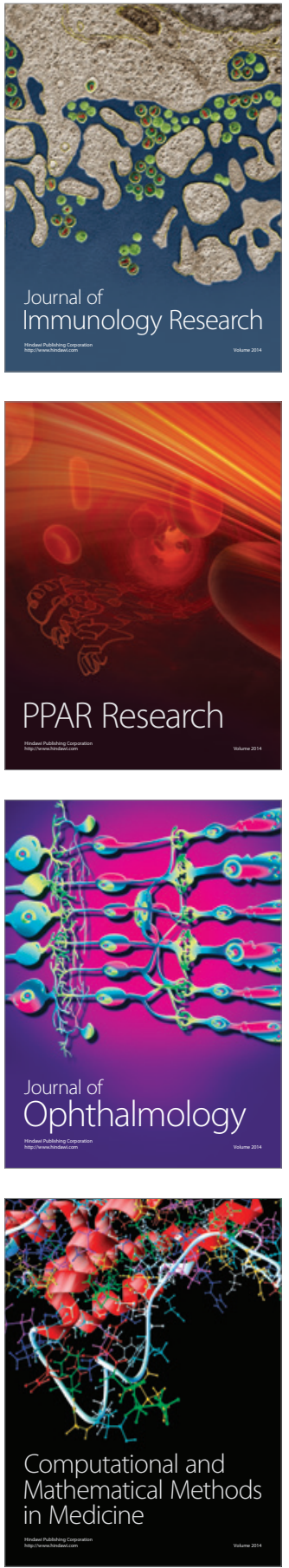

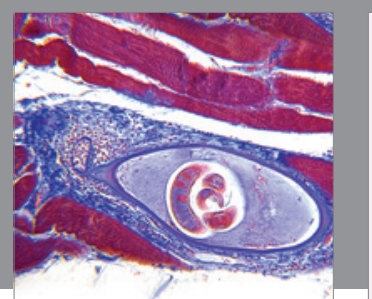

Gastroenterology Research and Practice

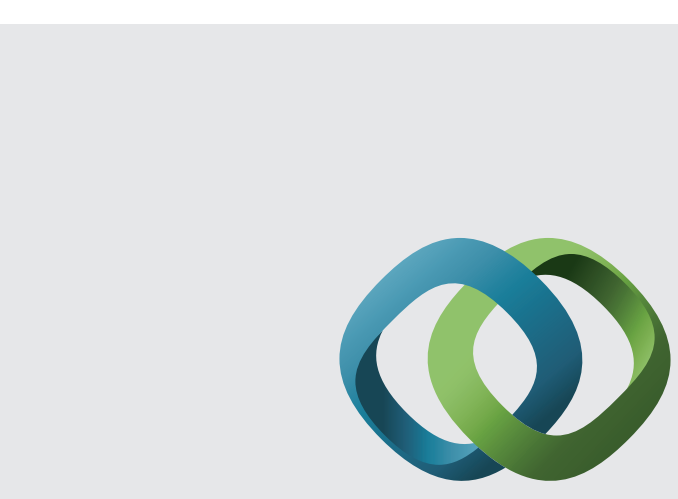

\section{Hindawi}

Submit your manuscripts at

http://www.hindawi.com
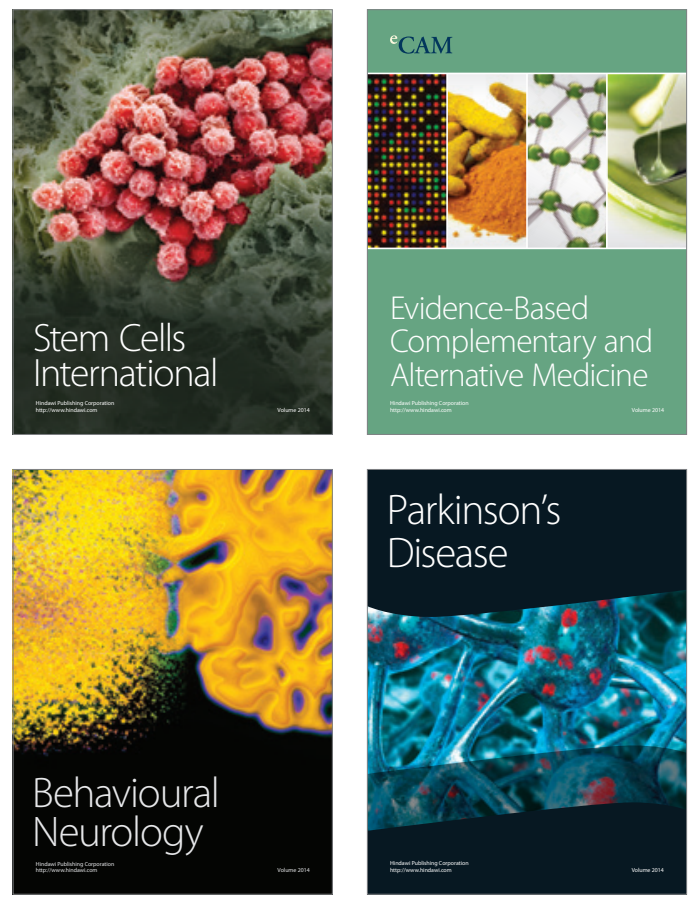
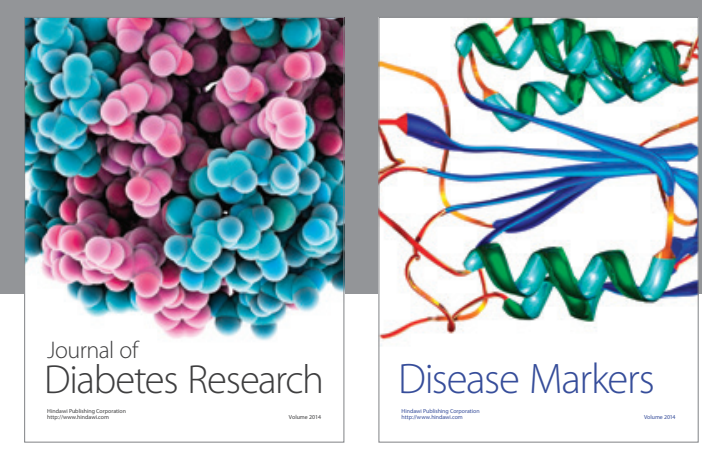

Disease Markers
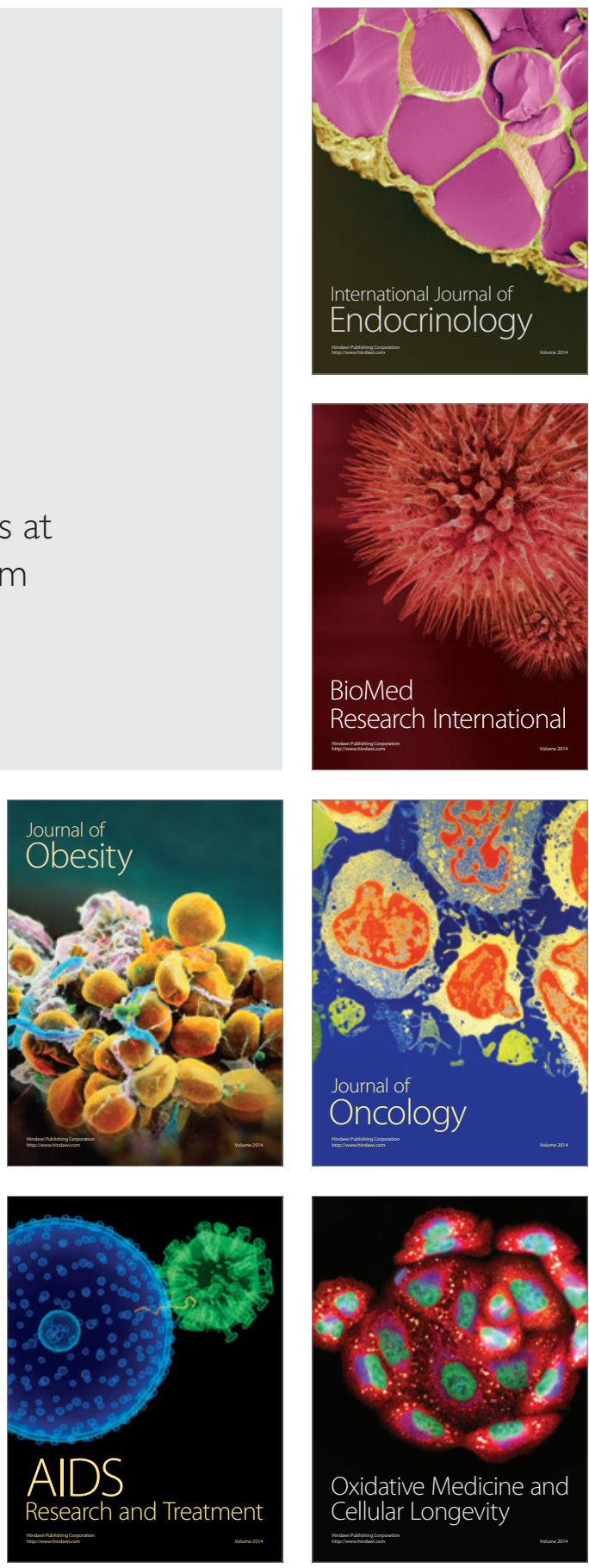